\title{
Thermal Imaging for Monitoring Rolling Element Bearings
}

\author{
by R. Schulz ${ }^{1,2}$, S. Verstockt ${ }^{3}$, J. Vermeiren ${ }^{4}$, M. Loccufier ${ }^{2}$, K. Stockman ${ }^{1}$ and S. Van Hoecke Vol, $^{1,3}$ \\ ${ }^{1}$ Ghent University - Department of Industrial System and Product Design - Graaf Karel de Goedelaan 5, B- \\ 8500 Kortrijk, Belgium [raiko.schulz@ugent.be, kurt.stockman@ugent.be] \\ ${ }^{2}$ Ghent University - Department of Electrical Energy, Systems and Automation - SYSTeMS Research Group - \\ Technologiepark Zwijnaarde 914, B-9052 Zwijnaarde, Belgium [mia.loccufier@ugent.be] \\ ${ }^{3}$ Ghent University - iMinds, Department of Electronics and Information Systems - Multimedia Lab - Gaston \\ Crommenlaan 8, Bus 201, B-9050 Ghent, Belgium [steven.verstockt@ugent.be, sofie.vanhoecke@ugent.be] \\ ${ }^{4}$ Xenics nv - Ambachtenlaan 44, B-3001 Leuven, Belgium [jan.vermeiren@xenics.com]
}

\begin{abstract}
This paper stems from a project to complement present condition monitoring techniques for offshore wind turbine drive trains by thermal imaging. In a first test setup, fully covered spherical roller bearings have been monitored. A methodology for analysing the thermal measurements is presented and applied for both healthy and faulty bearings. Independent of the ambient temperature, a bearing with inner raceway fault shows faster and higher temperature increase than the healthy bearing. Furthermore, the heat increase does not further propagate through the shaft, revealing the potential of thermal imaging for both fault detection and localization for drive train components.
\end{abstract}

\section{Introduction}

To operate offshore wind turbines in an economic perspective, a reliable operation needs to be assured such that downtime and maintenance costs remain low and energy generation guaranteed [1, 2]. Short-termed maintenance on high seas is very expensive and replacing broken components can take months [3]. Therefore, early and reliable fault detection is necessary to avoid more expensive consequential damage, or even a complete failure leading to a long loss of production [4].

In Figure 1, the main components of a gearbox-based wind turbine drive train are shown schematically. Because of their tribological nature, wind turbine drive train components such as gears and bearings are affected by friction and wear $[5,6]$. The consequences include vibrations, acoustic emissions and heat which can be monitored by different sensor-based techniques. Faults in the drive trains are the main cause for downtime [7, 8]. Bearing faults belong to the major issues in reliability of wind turbine drive trains, as the bearings must deal with cyclic and transient loading as well as with alignment issues [9]. Furthermore, the majority of wind turbine gearbox faults appear to initiate in the bearings and may propagate towards the gear teeth [10].

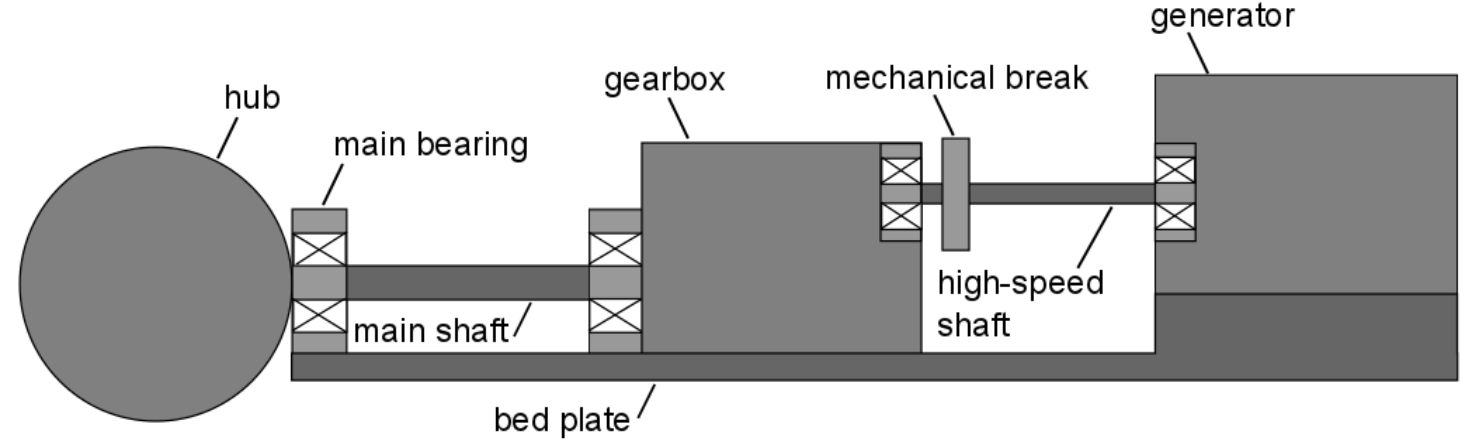

Fig. 1. Scheme of a wind turbine drive train with gearbox

Table 1 shows the fault clusters and major techniques for real-time monitoring of rolling element bearings. Different condition monitoring techniques can be implemented, whereas present techniques still show shortcomings in terms of real-time monitoring and data processing [11]. Vibrations and acoustic emissions propagate through the drive train structure which can make fault localization difficult and requires high expertise or detailed system models. Real-time oil analysis is usually limited to measuring oil quality and particle counts. More detailed information for identifying the faulty component and fault classification require onshore sample analysis which itself can already be costly regarding time and financing [7]. 
http://dx.doi.org/10.21611/qirt.2014.088

Table 1. Fault clusters and real-time condition monitoring techniques for rolling element bearings

\begin{tabular}{|c|c|c|c|c|c|c|}
\hline fault type & $\begin{array}{c}\text { water- } \\
\text { contamination }\end{array}$ & $\begin{array}{c}\text { hard-particle } \\
\text { contamination }\end{array}$ & $\begin{array}{c}\text { lubrication } \\
\text { faults }\end{array}$ & $\begin{array}{c}\text { electric } \\
\text { faults }\end{array}$ & $\begin{array}{c}\text { subsurface } \\
\text { faults }\end{array}$ & $\begin{array}{c}\text { surface } \\
\text { faults }\end{array}$ \\
\hline $\begin{array}{c}\text { lubricant } \\
\text { analysis }\end{array}$ & $\mathrm{X}$ & $\mathrm{X}$ & $\mathrm{X}$ & - & - & - \\
\hline $\begin{array}{c}\text { vibration } \\
\text { analysis }\end{array}$ & - & $\mathrm{X}$ & $\mathrm{X}$ & $\mathrm{X}$ & $\mathrm{X}$ & $\mathrm{X}$ \\
\hline $\begin{array}{c}\text { acoustic } \\
\text { emissions }\end{array}$ & - & $\mathrm{X}$ & $\mathrm{X}$ & $\mathrm{X}$ & $\mathrm{X}$ & $\mathrm{X}$ \\
\hline $\begin{array}{c}\text { thermal } \\
\text { imaging }\end{array}$ & - & $\mathrm{X}$ & $\mathrm{X}$ & $\mathrm{X}$ & $\mathrm{X}$ & $\mathrm{X}$ \\
\hline
\end{tabular}

Most bearing faults result in increased temperature which offers opportunities for using thermal imaging [12]. Thermal imaging enables real-time temperature monitoring and localization of temperature increases. Furthermore, it allows a spatial visualization of heat propagation in monitored areas. As increasing temperatures are usually a more local phenomenon, thermal imaging shows potential to improve fault detection and complement current state-of-the-art condition monitoring techniques [13, 14]. A multiple-sensor approach to combine classic techniques such as vibration analysis with thermal imaging is a promising alternative for enhanced and early fault detection, online component identification and real-time fault classification.

This paper analyses the potential of thermal imaging for monitoring rolling element bearings. After introducing the test setup, a methodology for analysing the thermal data is presented and applied on both healthy and faulty bearings.

\section{Experimental Setup}

A test setup, as schematically shown in Figure 2 is used for monitoring FAG 22205-E1-K spherical roller bearings ${ }^{1}$. As shown in Figure 4, these bearings consist of cylindrical rollers which manage high axial forces oscillating in both directions as well as radial forces. They are particularly designed to handle heavy loads such as in wind turbines. The close osculation between rollers and raceways supports uniform stress distribution. As it is usually the case in industrial applications such as wind turbine drive trains, the bearings are completely covered and sealed.

In this particular setup, the bearings have been mounted within FAG SNV052-F-L plummer block housings ${ }^{2}$. The shaft is solid Cf53, made of hardened and ground steel, and has a diameter of $20 \mathrm{~mm}$ with a h6 tolerance rate.

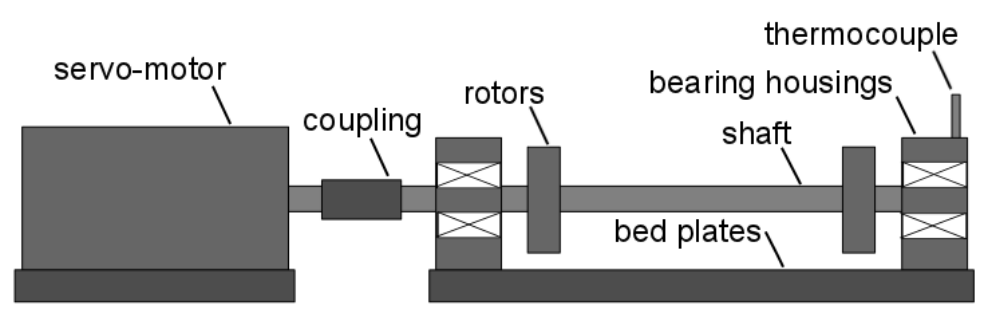

Fig. 2. Scheme of the test setup

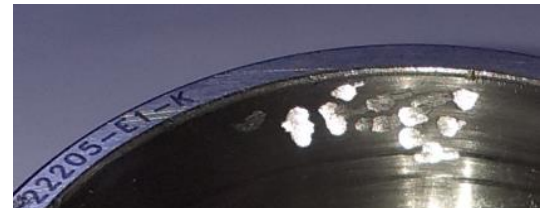

Fig. 3. Intentionally pre-damaged outer raceway

Beside intact bearings, intentionally pre-damaged bearings have been monitored as well. In particular, pitting as one of the most common faults with a variety of possible causes has been simulated by means of a milling machine. Figure 3 shows how small holes have been added in a triangular shape to the outer ring of a bearing. The same kind of fault has been added to the inner ring of another bearing and is discussed in this paper.

\footnotetext{
${ }^{1}$ http://medias.schaeffler.de/medias/en!hp.ec.br.pr/222..-E1-K\%20\%2b\%20H²2205-E1-K\%20\%2b\%2OH

2 http://medias.schaeffler.de/medias/en!hp.ec.br.pr/SNV\%20\%2b\%20222..-E1-
} 


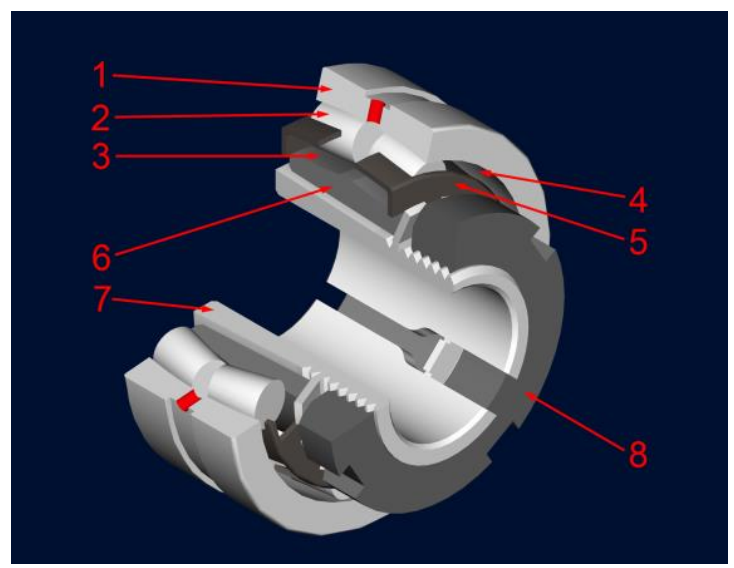

Table 2. Spherical roller bearing parts

\begin{tabular}{|c|l|}
\hline \multicolumn{2}{|l|}{ bearing parts } \\
\hline 1 & outer ring \\
\hline 2 & rolling element \\
\hline 3 & inner raceway \\
\hline 4 & outer raceway \\
\hline 5 & cage \\
\hline 6 & inner ring \\
\hline 7 & adapter sleeve \\
\hline 8 & groove nut \\
\hline
\end{tabular}

Fig. 4. 3D scheme of spherical roller bearing

Each test was running for one hour and at a rotational speed of 1,500 rotations per minute, which is a standard rotational speed for high-speed components in European wind turbine drive trains. For monitoring the setup, the Gobi$640-\mathrm{GigE}^{3}$, an uncooled long-wave infrared (LWIR) camera by Xenics, has been used at a frame rate of 6.25 frames per second. The thermocouples located behind the setup have been used to monitor the ambient temperature which is serving as reference temperature for the data processing.

\section{Methodology}

Thermal measurements have been performed for both healthy and faulty bearings. Before each measurement, the setup is cooled down to ambient temperature in order to receive a comparable starting situation and an understanding of the general heating up process.

All bearings have been monitored from different point of views. The analysis in this paper focusses on the camera location sideways of the setup which allows to monitor both bearing housing and shaft as shown in Figures 5 and 6. This point of view is expected to be most promising to monitor the effects of outer raceway faults as well as inner raceway faults. Figure 6 shows the thermal image taken from the side of the housing for the healthy bearing after a measurement period of sixty minutes.

Because both bearing housing and shaft show different temperature characteristics and noise effects such as reflections, regions of interests have been selected and further analyzed. Both two-dimensional and three-dimensional surface plots have been analyzed to determine the actual thermal characteristics of both healthy and faulty bearings as well as noise, and consequently support the choice of meaningful regions of interest. The upper housing is closest to the outer ring because of lower material thickness and is therefore selected as first region of interest. The bottom part of the shaft next to the bearing housing is expected to show heat increase based on both natural impacts such as shaft bending as well as bearing faults, and therefore selected as second region of interest.

\footnotetext{
3 http://www.xenics.com/en/infrared_camera/lwir_-_infrared_thermography_camera/gobi-640-gige__thermal_imaging_camera_with_gige_vision_interface.asp
} 


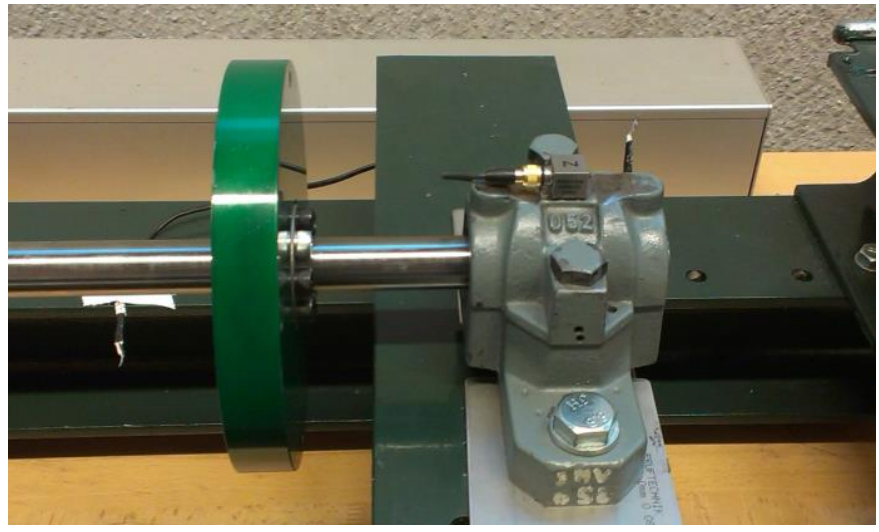

Fig. 5. Bearing housing and shaft from the side

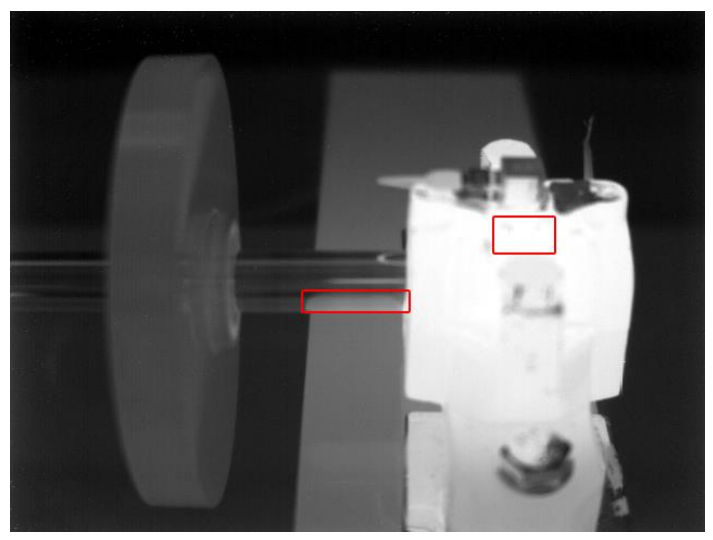

Fig. 6. Thermal image of bearing housing and shaft with regions of interest

To reduce the impact of environmental changes, all diagrams discussed in this paper show the temperatures relative to the ambient temperature. In other words, the ambient temperature is subtracted from the absolute temperatures. The ambient temperature is measured by thermocouples which can be seen in the back of the setup in Figure 5. By using relative temperatures instead of absolute temperatures, consistent results are obtained independent of the ambient temperature. Furthermore, this procedure significantly reduces step effects in the trend graphs caused by camera calibration and therefore improves readability of the data.

For each bearing, four measurements have been performed with the discussed camera location. The inner raceway fault consistently shows higher temperatures than the healthy bearing as well as faster temperature increase. However, the difference in maximum temperatures between both bearings at the end of each measurement varies. Therefore, average trends are created from four single measurements for each bearing. Furthermore, both the temperature gain and time constants are discussed for these average trends. The relative temperature gain is the difference between the relative temperatures of the system in non-operating state and after sixty minutes in operating state. In order to receive the time constants, the trend graphs of both healthy bearing and inner raceway fault are matched with first-order dynamics. The time constant of the system response is the time which is required by the step response to reach $63 \%$ of its final value [15].

\section{Results}

In the following sections, the previously discussed methodology is applied for both healthy and faulty bearings. First, the surfaces of both bearing housing and shaft are analyzed to determine regions of interests for trend analysis. Each of the presented surface plots displays the last image which has been taken at the end of the corresponding measurement period of sixty minutes.

\subsection{Frame-wise analysis of the bearing housing}

As shown in Figure 7, the non-uniform surface of the bearing housing leads to different temperature characteristics. The material of the upper housing is thinner and leads to faster heat-increase than for the bottom part. The screw in the upper center of the housing as well as the polished surface on top of the housing cause distinct drops in the measurements, making these regions unsuitable for further analysis. The central upper region of the housing is closest to the outer bearing ring because of thinner material and shows the highest temperatures. Therefore, this region is chosen for further analysis. 


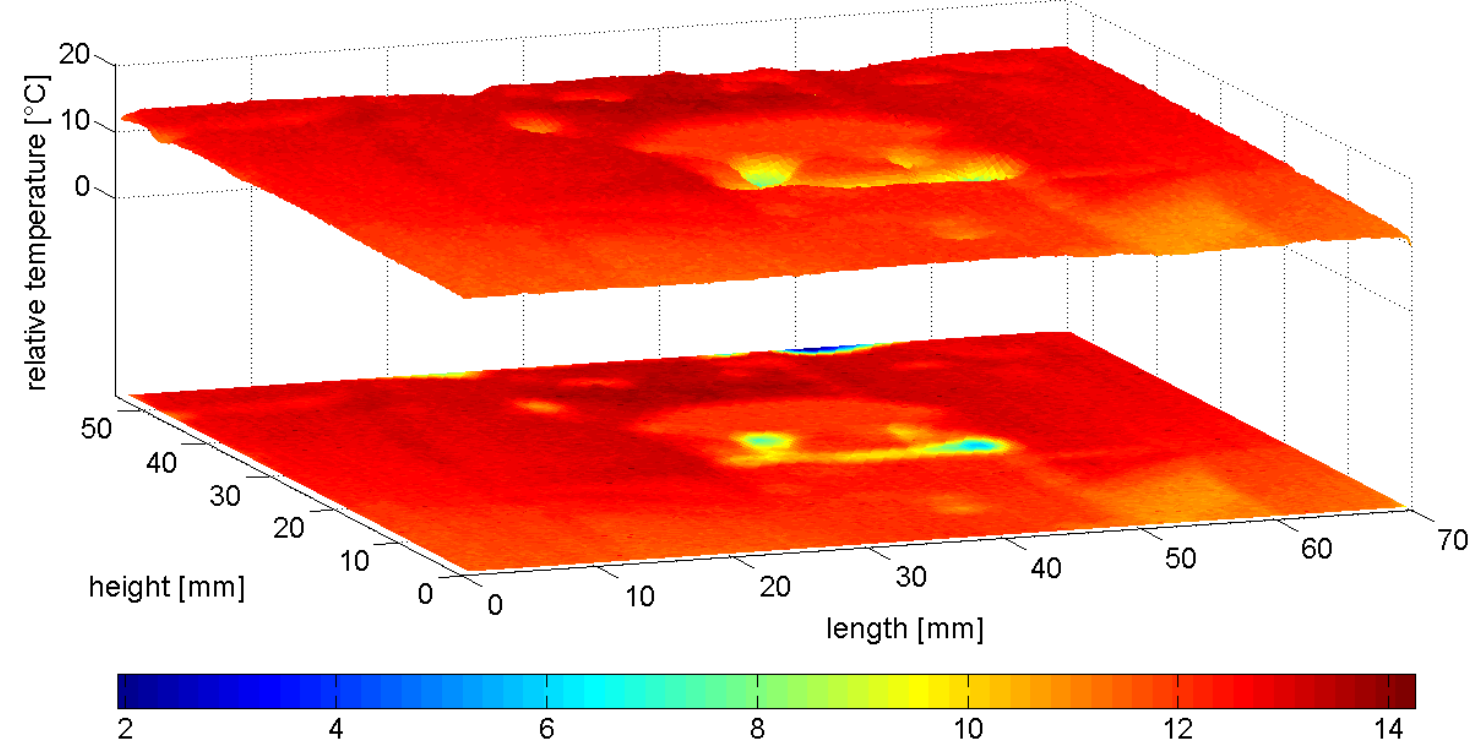

Fig. 7. Three-dimensional surface plot of the housing for the healthy bearing

The region of interest is shown for the healthy bearing in Figure 8 and for the bearing with inner raceway fault in Figure 9. As both images show noise caused by reflection of light, the thermal measurements need to be analysed carefully. For the inner raceway fault, higher temperatures are monitored as well as a stronger heat propagation across the surface which is indicated by the more uniform color representation.

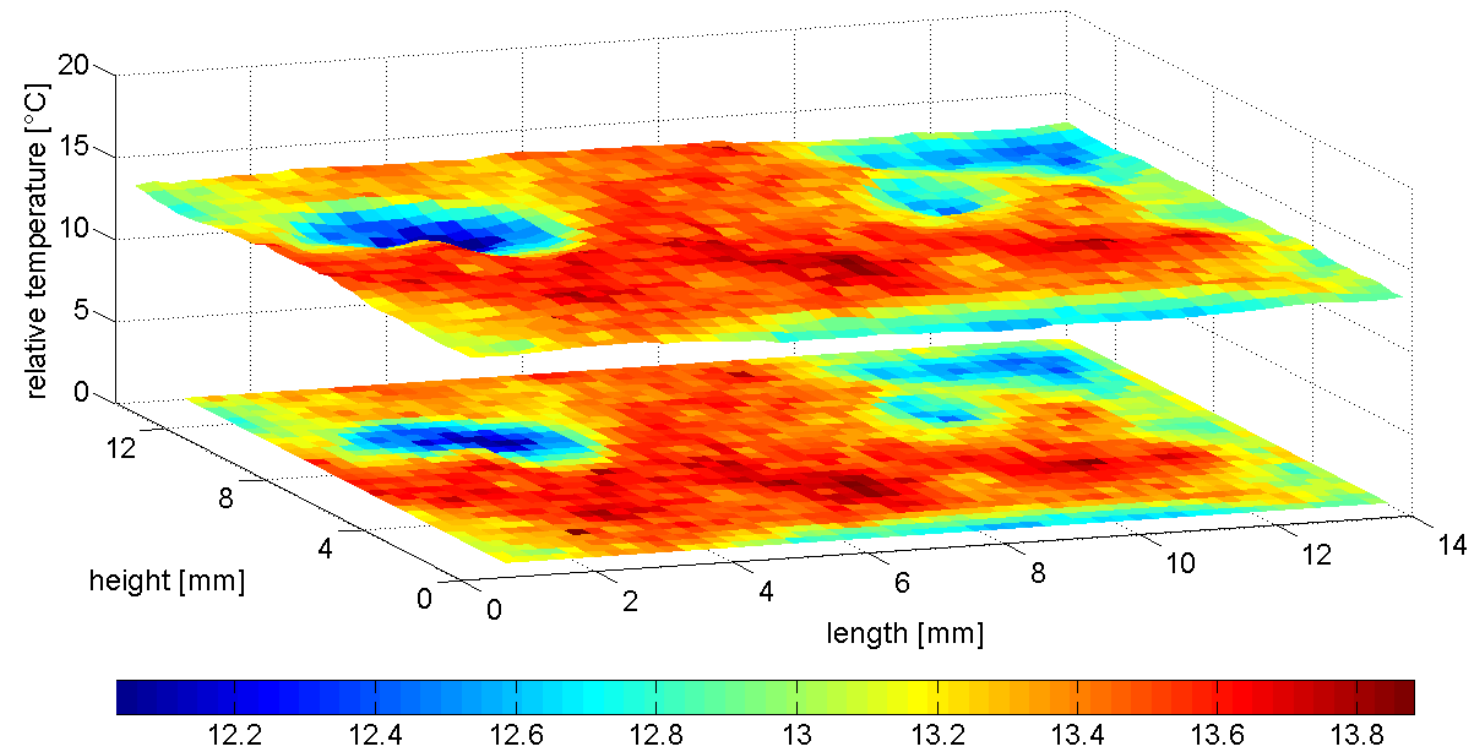

Fig. 8. Housing region of interest for healthy bearing 


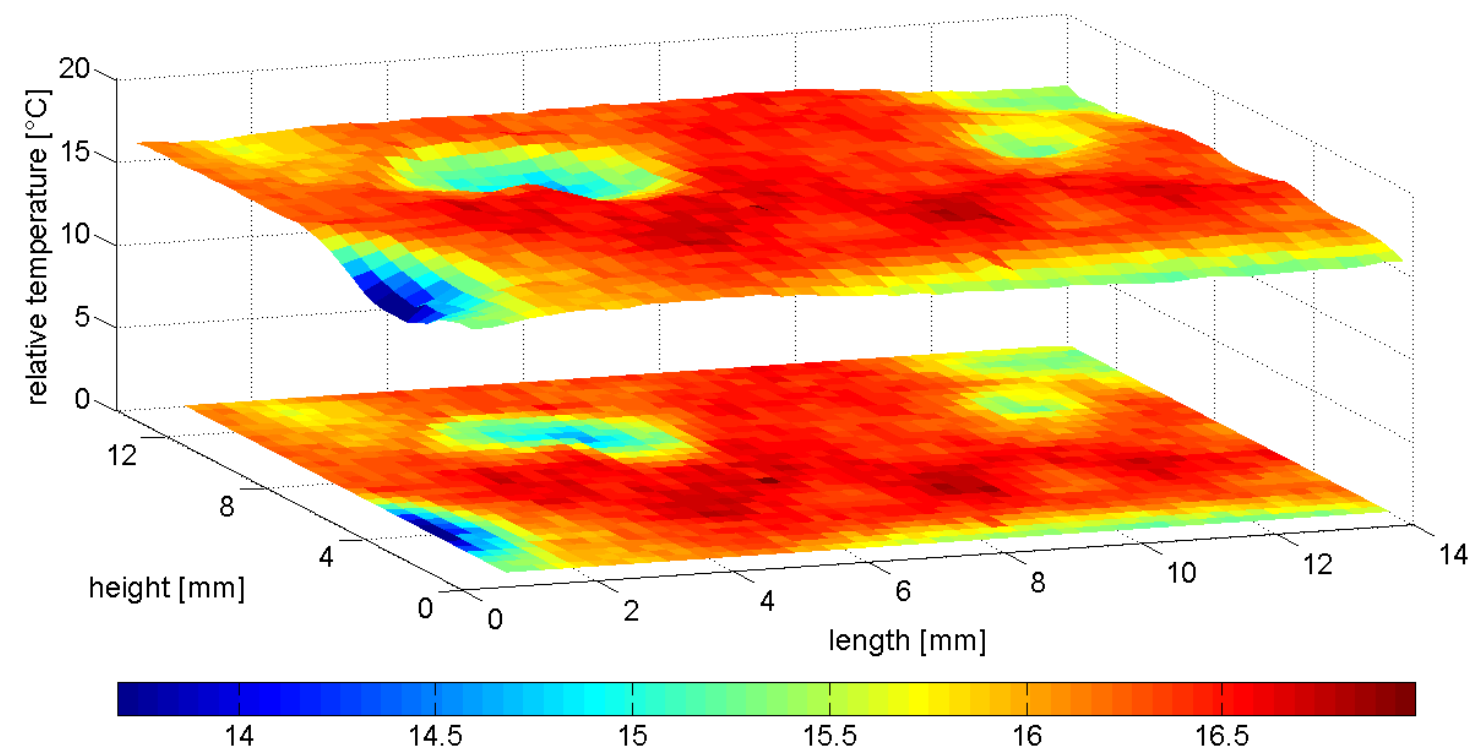

Fig. 9. Housing region of interest for bearing with inner raceway fault

\subsection{Frame-wise analysis of the shaft}

The second region of interest is located at the shaft. Increased temperatures have been monitored in the bottom right shaft next to the bearing housing. This impact becomes more distinct in the surface plots in Figures 10 and 11 which represent the complete shaft part between bearing housing and mass rotor for both healthy and faulty bearing.

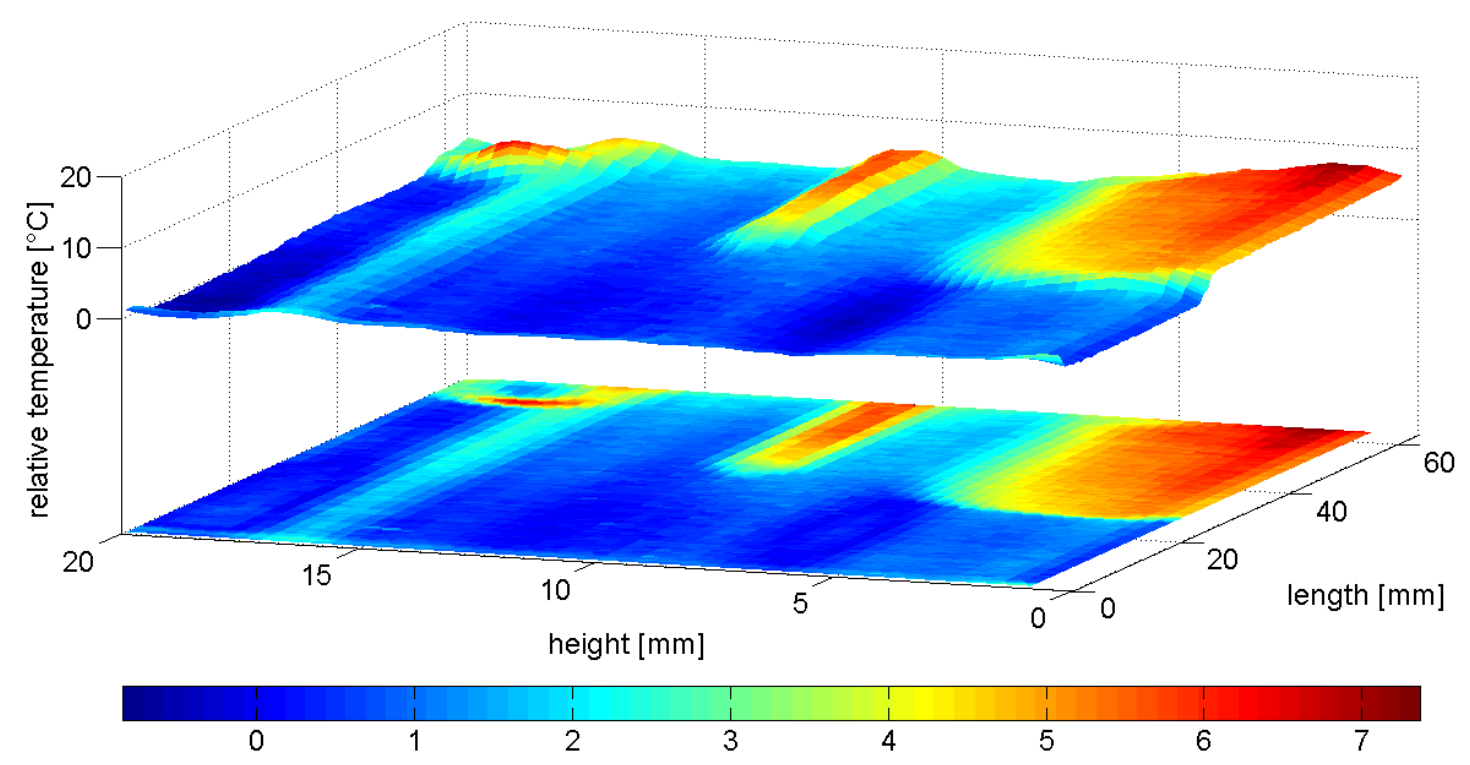

Fig. 10. Three-dimensional surface plot of shaft from side view for healthy bearing 


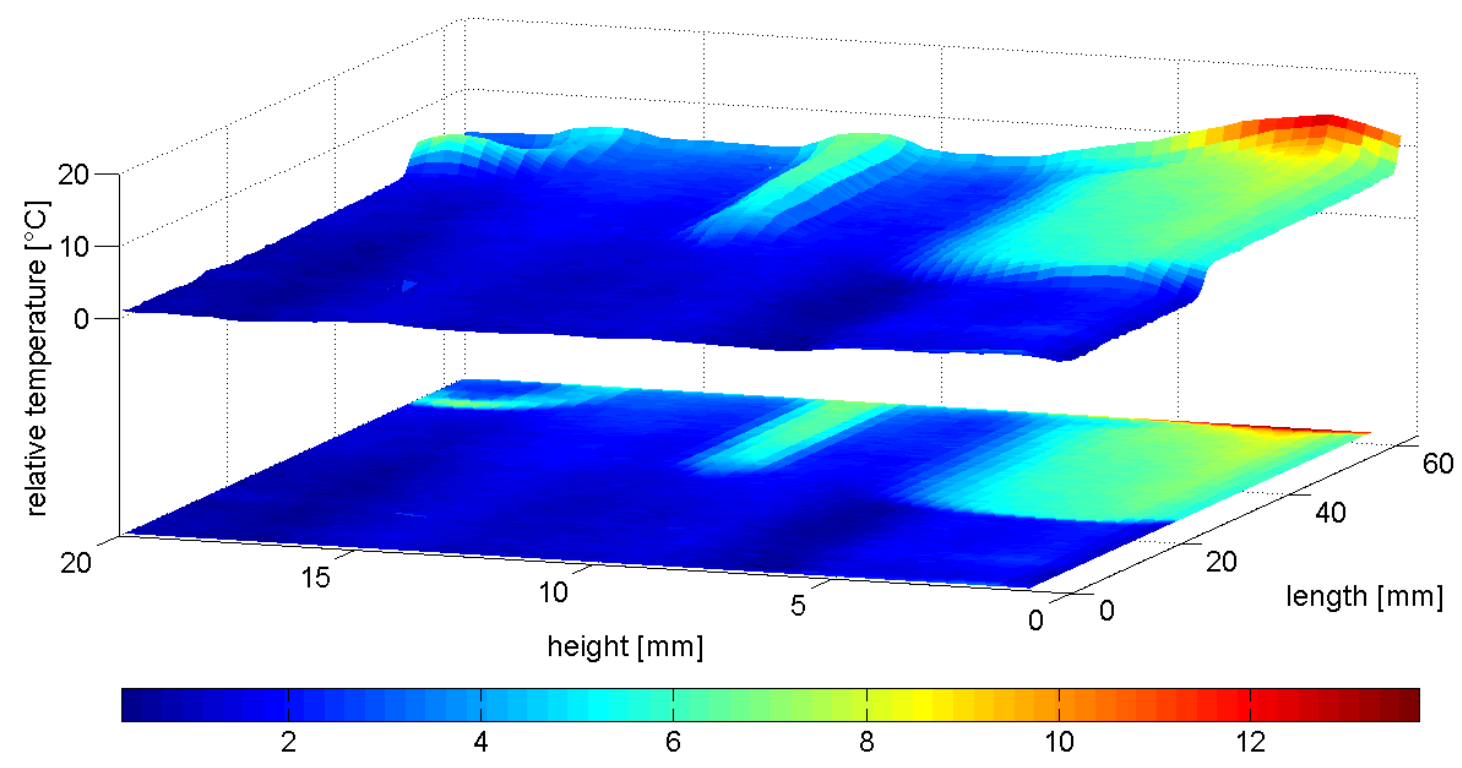

Fig. 11. Three-dimensional surface plot of shaft from side view for bearing with inner raceway fault

The shaft shows distinct heat increase next to the bearing housing for both healthy and faulty bearings. As the housing is sealed and the rotation of the shaft seems to cause a cooling effect, this heat increase only occurs for a small region. Central and upper shaft show lower temperatures and in fact no distinguishable heat increase for both healthy and faulty bearings. The peaks in the upper shaft are caused by reflection of light. It was monitored that the locations of the reflections on the shaft are not fixed but slightly oscillating up- and downwards. Because of these characteristics, further analysis of the shaft focusses on the heat increase in the bottom part next to the housing.

\subsection{Trend analysis}

The presented surface plots give insight about the temperature distribution for regions of interest at a specific point in time, more precisely after sixty minutes of system run time. Whereas the region of interest at the housing shows a more uniform temperature distribution, the shaft is strongly affected by reflection of light and significant heat increase is only indicated in its bottom right corner next to the bearing housing. However, a first trend analysis of the shaft did not allow a reliable distinction between healthy and faulty bearings. Therefore, the trend analysis in this paper focusses on the region of interest in the upper center of the housing. The central point of this region, which is not affected by reflection of light, is selected for the following trend analysis.

Figures 12 and 13 show the average relative temperature increases and step responses for the central point of the region of interest on the housing, independent of the ambient temperature. Whereas the thermocouples have shown only little differences in the ambient temperature, the temperatures of the housing clearly differ for the different bearings. In particular, the temperatures for the inner raceway fault increase faster than for the healthy bearing.

Whereas the inner raceway fault shows a first-order behavior straight from the beginning, the healthy bearing shows more a second-order behavior. The second-order behavior is approximated by a first-order model with dead time. The dead time defines the initial time required by the trend to show first-order behavior. In particular, a dead time of 48 seconds is determined for the healthy bearing. 


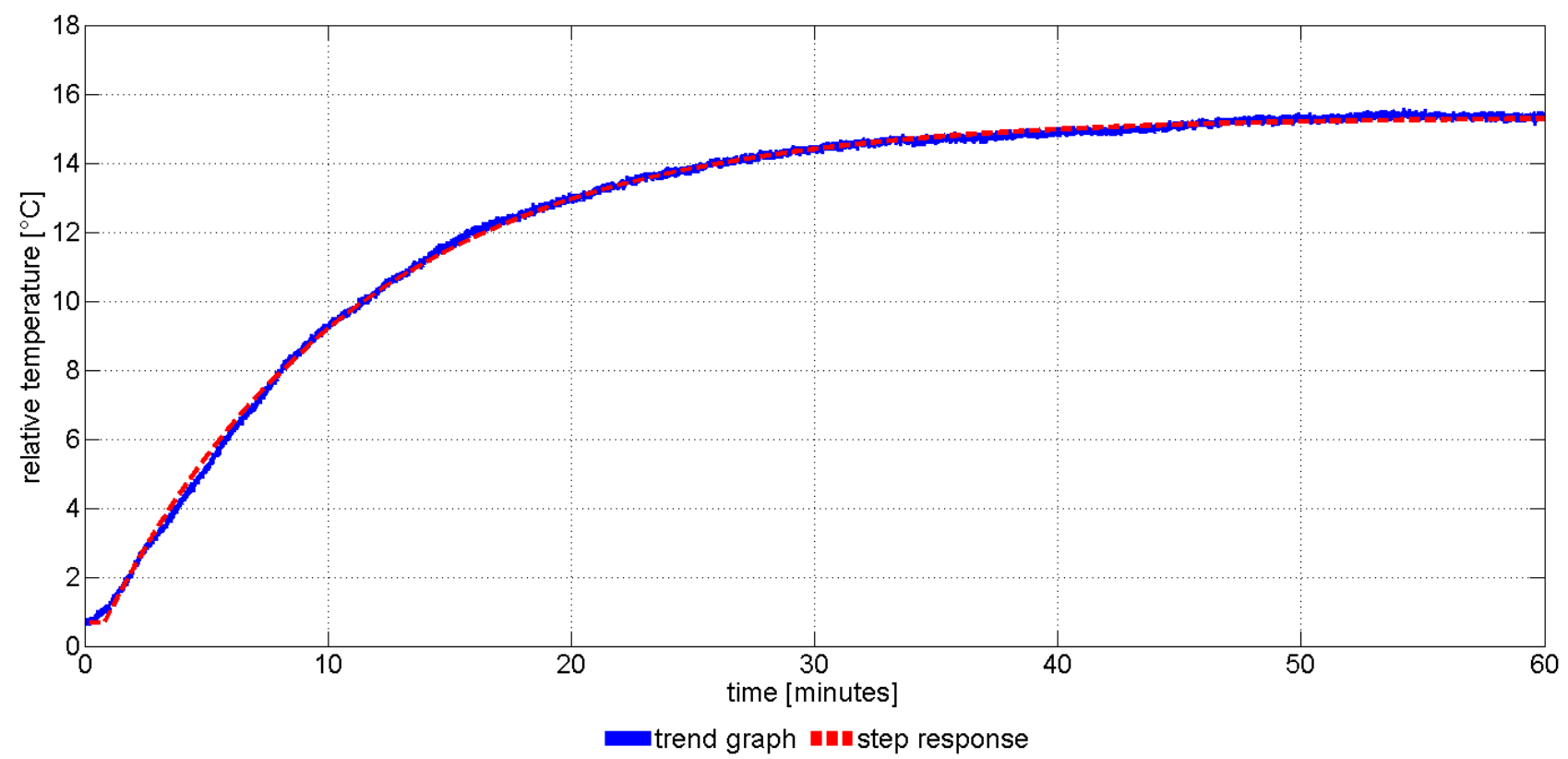

Fig. 12. Relative temperature trend and step response of the housing for healthy bearing

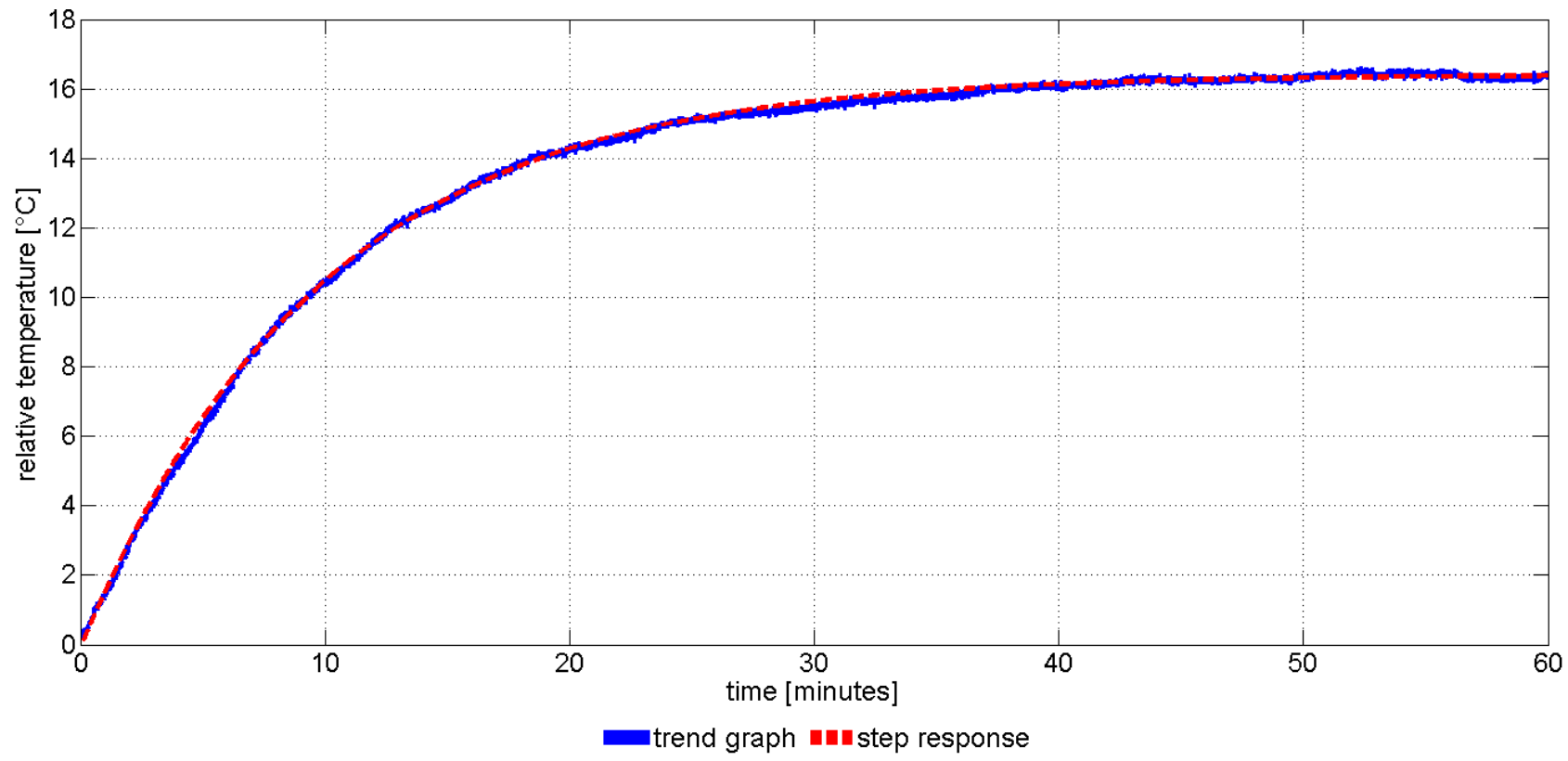

Fig. 13. Relative temperature trend and step response of the housing for bearing with inner raceway fault

Table 3 shows the relative temperature gains of the housing for both healthy and faulty bearing after sixty minutes. In Table 4, the time constants are shown for the temperature increase of both healthy and faulty bearing. The stronger temperature gain and the faster heat increase for the bearing with inner raceway fault allow the distinction of healthy and faulty bearings and reveal potential for fault detection by means of thermal imaging.

Table 3. Relative temperature gain after sixty minutes

\begin{tabular}{|l|r|r|}
\hline \multicolumn{3}{|l|}{ relative temperature gains for housing in ${ }^{\circ} \mathrm{C}$} \\
\hline bearing & healthy & inner raceway fault \\
\hline temperature & 14.67 & 16.28 \\
\hline
\end{tabular}

Table 4. Time constants for both regions of interests

\begin{tabular}{|l|rr|r|}
\hline \multicolumn{3}{|l|}{ time constants in minutes } \\
\hline bearing & healthy & inner raceway fault \\
\hline time constant & 10.6 & 9.8 \\
\hline dead time & 0.8 & 0.0 \\
\hline
\end{tabular}




\section{Conclusions}

Fully covered and sealed rolling element bearings, such as they are common in industrial applications, have been monitored by a thermal camera. Different temperature increases have been monitored for a healthy bearing and a bearing with inner raceway fault. The inner raceway fault leads to a faster and higher temperature increase of the bearing housing compared to the healthy bearing. Although the bearings have been covered, the differences in the average temperature trends illustrate the potential of thermal cameras to monitor covered machinery such as in wind turbines. Whereas vibrations propagate through the drive train and fault localization requires high expertise, temperature increase is a more local impact as it can be seen in the temperature propagation from the housing towards the shaft. This supports the potential of thermal cameras for not just visualizing but also localizing faults, making them a promising sensor type for condition monitoring of wind turbine drive trains.

\section{REFERENCES}

[1] Entezami M., Hillmansen S., Roberts C., "Distributed Fault Detection and Diagnosis for Wind Farms", Annual Conference of the Prognostics and Health Management Society, Portland (USA), 2010

[2] Costinas S., Diaconescu I., Fagarasanu I., "Wind Power Plant Condition Monitoring", $3{ }^{\text {rd }}$ WSEAS International Conference on Energy Planning, Energy Saving, Environmental Education, Tenerife (Spain), 2009

[3] Daneshi-Far Z., Capolino G.A., Henao H., "Review of Failures and Condition Monitoring in Wind Turbine Generators". XIX International Conference on Electrical Machines, Rome (Italy) 2010.

[4] Kusiak A., Verma A., "Prediction of Status Patterns of Wind Turbines: A Data Mining Approach". Journal of Solar Energy Engineering, vol. 133, American Society of Mechanical Engineers, New York (USA), 2011.

[5] Hannon W.M., "Rolling Bearing Condition Monitoring", Encyclopedia of Tribology, pp. 2812-2820, Springer Science+Business Media, New York (USA), 2013

[6] Kang, Y.S., "Rolling Bearing Contact Fatigue", Encyclopedia of Tribology, pp. 2820-2824, Springer Science+Business Media, New York (USA), 2013

[7] Sheng S., Veers P., "Wind Turbine Drivetrain Condition Monitoring" Applied Systems Health Conference, Virginia Beach (USA), 2011.

[8] Lu B., Li Y., Wu X., Yang Z., "A Review of Recent Advances in Wind Turbine Condition Monitoring and Fault Diagnosis", IEEE Power Electronics and Machines in Wind Applications, Lincoln (USA), 2009

[9] Terrell E.J., Needelman W.M., Kyle J.P., "Wind Turbine Tribology". Green Tribology - Biomimetics, Energy Conservation and Sustainability, pp. 483-530, Springer International Publishing, Cham (Switzerland), 2012.

[10] Musial W., Butterfield S., "Improving Wind Turbine Gearbox Reliability". European Wind Energy Conference, Milan (Italy), 2007

[11] Zhang Z., Verma A., Kusiak A., "Fault Analysis and Condition Monitoring of the Wind Turbine Gearbox", IEEE Transactions on Energy Conversion, Vol. 27, No. 2, pp. 526-535, 2012

[12] Hannon W.M., Houpert L., "Rolling Bearing Heat Transfer and Temperature", Encyclopedia of Tribology, pp. 2831-2839, Springer Science+Business Media, New York (USA), 2013

[13] Tavner P.J., "Review of condition monitoring of rotating electrical machines", IET Electric Power Applications, Vol. 2, No. 4, pp. 215-247, 2008

[14] García Márquez F.P., Tobias A.M., Pinar Pérez J.M., Papaelias M., "Condition Monitoring for Wind Turbines: Techniques and Methods", Renewable Energy, Vol. 46, pp. 169-178, 2012

[15] Nise N.S., "Control Systems Engineering", 6 th Edition, pp. 166-168, John Wiley \& Sons (Asia), Singapore, 2011 